\title{
Clinical Features, Treatment and Monitoring in Patients With Polymyalgia Rheumatica
}

\author{
Fatma Gül YURDAKUL, Hatice BODUR, Filiz SİVAS, Bedriye BAŞKAN, Filiz ESER, Onur YILMAZ
}

Department of Physical Medicine and Rehabilitation, Ankara Numune Training and Research Hospital, Ankara, Turkey

\begin{abstract}
Objectives: This study aims to evaluate the clinical symptoms and laboratory findings of Turkish patients with polymyalgia rheumatica. Patients and methods: Clinical data of 41 patients ( 9 males, 32 females; mean age $65.5 \pm 7.6$ years; range 60 to 80 years) with polymyalgia rheumatica were retrospectively evaluated. Patients' clinical symptoms, laboratory findings, therapies and therapeutic responses were analyzed.

Results: The most common symptoms were bilateral shoulder pain (59.9\%) and morning stiffness (48.78\%). Mean erythrocyte sedimentation rate at diagnosis was $66.8 \pm 22.5 \mathrm{~mm} / \mathrm{h}$, while mean C-reactive protein value was $48.7 \pm 25.8 \mathrm{mg} / \mathrm{dL}$. In the third week of corticosteroid treatment, good response to treatment was detected in 33 patients (80.5\%). Mean age of patients who gave good response to treatment (67.2 \pm 6.7$)$ was higher than mean age of patients who gave poor or no response to treatment $(58.5 \pm 7.8)(p=0.009)$.

Conclusion: Patients' clinical features, laboratory findings, initial steroid doses, and responses to corticosteroid therapy were consistent with the literature. However, the rate of morning stiffness was high and peripheral arthritis was rare. Giant cell arteritis was not detected in patients with polymyalgia rheumatica. Good response to early steroid treatment was observed in older patients. Rate of relapse was low. Further studies are required to evaluate factors affecting response to treatment, remission, and relapse.

Keywords: Clinical features; polymyalgia rheumatica; treatment response.
\end{abstract}

Polymyalgia rheumatica (PMR) is a chronic, inflammatory disorder characterized by morning stiffness, aching in the shoulder, and pelvic girdles in people aged 50 years and older. ${ }^{1}$ In 1888, Bruce described PMR as senile rheumatic gout with proximal muscular syndrome. ${ }^{2}$ To the best of our knowledge, there are no specific diagnostic tests for PMR. Diagnosis is based on clinical presentation, evidence of systemic inflammation, and response to corticosteroids. Over the years, various classification criteria have been developed by Bird et al., ${ }^{3}$ Chuang et al., ${ }^{4}$ and Healey. ${ }^{5}$ More recently, new classification criteria have been developed by a group of international specialists with the official endorsement of the American Collage of Rheumatology and of the European League Against Rheumatism. ${ }^{6}$ A new scoring algorithm was developed based on morning stiffness ( $>45$ minutes), hip pain and/ or limited range of motion, ultrasound findings absence of rheumatoid factors (RF) and/or anticitrullinated protein antibodies, and absence of peripheral joint pain. Adding ultrasound into the criteria increased the specificity and was helpful for differential diagnosis testing. Conversely, response to corticosteroids was not included in new classification criteria due to the possibility of several conditions giving false positive responses to treatment. ${ }^{6}$ There are several studies about the epidemiology, clinical characteristics, and treatment options of patients with PMR..$^{7-15}$ To our knowledge, the epidemiological study of PMR within Turkish patients is limited in the literature. In this study, we aimed to evaluate the clinical symptoms and laboratory findings of Turkish patients with PMR. Additionally, 
therapeutic responses as well as relapses and remissions were evaluated.

\section{PATIENTS AND METHODS}

A total of 41 patients ( 9 males, 32 females; mean age $65.5 \pm 7.6$ years; range 60 to 80 years) who were being followed-up at least for one year in the Department of Physical Medicine and Rehabilitation were included. Information about patients' clinical characteristics, demographic data, concomitant diseases, family history, and treatment regime were obtained retrospectively from the records. Patients were classified as PMR according to Bird's criteria: (i) bilateral shoulder pain and stiffness or both; (ii) onset of illness within two weeks; (iii) initial erythrocyte sedimentation rate (ESR) $>40 \mathrm{~mm} / \mathrm{h}$; (iv) duration of stiffness $>1 \mathrm{~h}$; (v) age 65 years or older; (vi) depression or weight loss or both; and (vii) bilateral upper arm tenderness. If three or more of the seven criteria were fulfilled, a diagnosis of probable PMR was made. ${ }^{3}$ Additionally, initial symptoms and signs, physical examination findings, and complaints which were added during the follow-up were analyzed. Laboratory findings including compound blood account, ESR, C-reactive protein (CRP), RF, and liver and kidney function tests were collected.

Treatment for osteoporosis and gastric symptoms were observed. Patients receiving bisphosphonates and/or calcium and vitamin D preparations for osteoporosis were evaluated. The use of proton pump inhibitors or $\mathrm{H}_{2}$ antagonists for gastric symptoms was assessed.

Initial dose of corticosteroids, use of diseasemodifying antirheumatic drugs (DMARDs) therapy, response to corticosteroids, and remission and relapse were detected. Steroid doses were calculated as daily prednisolone equivalents. Response to treatment was evaluated in two parts: (i) good response and (ii) poor/no response. Good response was defined as completely or almost completely improved clinical symptoms with significantly reduced acute phase reactants, and normal levels of ESR and/or CRP within three weeks of starting steroid treatment. Poor response was defined as insufficiently improved clinical symptoms and levels of acute phase reactants in the first three weeks of treatment. No response was defined as insignificant or no changes in symptoms and acute phase reactants in the first three weeks. Remission was defined as the absence of clinical symptoms and normal levels of acute phase reactants without using any drugs which controls PMR. Relapses were defined as reappearance of clinical symptoms with elevated ESR or CRP levels in a patient receiving steroid treatment or after disuse of steroids.

\section{Statistical analysis}

Statistical analysis was performed using SPSS for Windows version 18.0 (SPSS Inc., Chicago, IL, USA) software program. Simple descriptive statistics including mean, median, and standard deviation were used to describe the data. Comparisons were performed using Mann-Whitney U test for continuous variables and either Chi-square test or Fisher's exact test for categorical variables. Statistical significance was defined as a $\mathrm{p}$ value $\leq 0.05$.

\section{RESULTS}

An investigation of presence of any comorbid chronic diseases revealed that seven patients had diabetes mellitus, four had coronary artery disease, one had hypothyroidism, one had chronic renal failure, and 20 had hypertension. Table 1 shows the baseline demographics of the study population.

Most common symptoms were bilateral shoulder pain $(59.9 \%)$ and morning stiffness (48.78\%). Peripheral arthritis was detected in four patients, two having knee arthritis, one having

\begin{tabular}{|lccc|}
\hline $\begin{array}{l}\text { Table 1. Baseline demographics } \\
\text { polymyalgia rheumatica }\end{array}$ & & & \\
\hline & $\mathrm{n}$ & $\%$ & Mean $\pm \mathrm{SD}$ \\
\hline Age at onset of symptoms (years) & & & $65.5 \pm 7.6$ \\
$\quad<50$ & 2 & 4.87 & \\
$>80$ & 2 & 4.87 & \\
$60-80$ & 33 & 80.48 & \\
Sex & 32 & 78.04 & \\
$\quad$ Female & 9 & 21.96 & \\
$\quad$ Male & & & \\
Existing chronic disease & 20 & 48.78 & \\
$\quad$ Hypertension & 7 & 17.07 & \\
Diabetes mellitus & 4 & 9.75 & \\
Coronary artery disease & 1 & 2.43 \\
$\quad$ Chronic renal failure & 1 & 2.43 & \\
$\quad$ Hypothyroidism & & & \\
SD: Standard deviation. & &
\end{tabular}


Table 2. Clinical characteristics of patients with polymyalgia rheumatica

\begin{tabular}{|c|c|c|c|}
\hline Primary symptoms & $\mathrm{n}$ & $\%$ & Mean \pm SD \\
\hline Bilateral shoulder pain & 23 & 59.09 & \\
\hline Morning stiffness & 20 & 48.78 & \\
\hline Myalgia & 16 & 39.02 & \\
\hline Hip girdle & 8 & 19.50 & \\
\hline Fatigue & 7 & 17.07 & \\
\hline Distal arthritis & 4 & 9.75 & \\
\hline Erythrocyte sedimentation rate $(\mathrm{mm} / \mathrm{h})$ & & & $66.8 \pm 22.5$ \\
\hline$<20$ mm/h (normal) & 2 & 4.87 & \\
\hline C-reactive protein (mg/dL) & & & $48.7 \pm 25.8$ \\
\hline$\leq 1 \mathrm{mg} / \mathrm{dL}$ (normal) & 3 & 7.31 & \\
\hline
\end{tabular}

wrist arthritis, and one having wrist arthritis with metacarpophalangeal joints. None of the patients was diagnosed as giant cell arteritis. Mean ESR at diagnosis was $66.8 \pm 22.5 \mathrm{~mm} / \mathrm{h}$ with two of the patients (4.87\%) having normal ESR $(<20 \mathrm{~mm} / \mathrm{h})$. Mean CRP was $48.7 \pm 25.8 \mathrm{mg} / \mathrm{dL}$ and normal CRP ( $\leq 1 \mathrm{mg} / \mathrm{dL}$ ) was observed in three patients. RF values of 36 patients were obtained and a positive RF was determined in $8.33 \%(n=3)$ of patients. Table 2 shows clinical characteristics and laboratory findings of the patients.

Dyspeptic complaints of patients and the use of drugs for gastric symptoms were evaluated. Gastric prophylaxis (with proton pump inhibitors or $\mathrm{H}_{2}$ antagonists) was prescribed to 34 patients (82.9\%). Thirteen patients (31.7\%) had a history of dyspeptic symptoms before the diagnosis of PMR.

Twenty-six patients (63.41\%) received a prescription for osteoporosis (bisphosphonate and/or calcium + vitamin D). Nine patients $(21.95 \%)$ were using calcium + vitamin D supplements alone while 17 patients (41.5\%) were using bisphosphonate and calcium + vitamin D supplements together. The remaining 15 patients did not use any drug for osteoporosis.

Mean initial dose of steroid was $17.4 \pm 4.2 \mathrm{mg} /$ day. The most frequent starting dose was $20 \mathrm{mg} /$ day (in 56.1\% of patients), while the second was $15 \mathrm{mg} /$ day (in $26.8 \%$ of patients). Six patients (14.6\%) had received $10 \mathrm{mg} /$ day, and one patient $(2.4 \%)$ had received $30 \mathrm{mg} /$ day prednisolone at the beginning of the treatment. Good response to initial steroid was observed in 33 patients $(80.5 \%)$ in the first three weeks of treatment. Eight patients had poor or no response in the first three weeks. Patients with an inadequate response to steroid treatment had received a higher dose of prednisolone according to their clinical and laboratory findings. Improved clinical symptoms and normal ESR/CRP were observed in six patients after increasing steroid dose. DMARD (methotrexate; MTX) was used in two patients (4.87\%). MTX was started with a dose of $10 \mathrm{mg} /$ week.

We evaluated age, sex, distal arthritis, ESR, $\mathrm{CRP}$, and dose of initial steroid in patients with or without good response in the first three weeks. Mean age of patients who had good response was $67.2 \pm 6.7$, whereas mean age of those with poor/no response was $58.5 \pm 7.8$ $(p=0.009)$. Table 3 shows the analysis of clinical characteristics and laboratory findings in the good response and poor/no response groups.

Seven patients (17.1\%) had remission and six patients (14.63\%) had relapse at least once during the monitoring. Two patients had more than two relapses. Two patients had relapse after the remission and four patients had relapse when they were still receiving steroid treatment.

Table 3. Clinical characteristics and laboratory findings in groups of good response and poor/no response

\begin{tabular}{|c|c|c|c|c|c|c|c|}
\hline & \multicolumn{3}{|c|}{$\begin{array}{c}\text { Good response group } \\
(n=33)\end{array}$} & \multicolumn{3}{|c|}{$\begin{array}{l}\text { Poor/no response group } \\
\qquad(\mathrm{n}=8)\end{array}$} & \multirow[b]{2}{*}{$p$} \\
\hline & $\mathrm{n}$ & $\%$ & Mean \pm SD & $\mathrm{n}$ & $\%$ & Mean \pm SD & \\
\hline Age & & & $67.2 \pm 6.7$ & & & $58.5 \pm 7.8$ & 0.009 \\
\hline Female & 27 & 81.8 & & 5 & 62.5 & & 0.342 \\
\hline Peripheral arthritis & 2 & 6.1 & & 2 & 25.0 & & 0.165 \\
\hline Erythrocyte sedimentation rate $(\mathrm{mm} / \mathrm{h})$ & & & $66.2 \pm 26.4$ & & & $62.3 \pm 7.5$ & 0.974 \\
\hline C-reactive protein (mg/dL) & & & $48.3 \pm 28.1$ & & & $45.1 \pm 29.3$ & 0.754 \\
\hline Initial prednisolone dose (mg/day) & & & $18.0 \pm 3.9$ & & & $15.0 \pm 4.6$ & 0.088 \\
\hline Remission & 6 & 18.01 & & 1 & 12.5 & & 0.702 \\
\hline
\end{tabular}




\section{DISCUSSION}

Polymyalgia rheumatica is a common chronic inflammatory disease that develops in older persons who are conventionally treated with long-term corticosteroids. ${ }^{6}$ We described clinical features of patients with PMR and analyzed their therapeutic responses. PMR typically affects people 50 years of age or older and its incidence increases with age, peaking at $70-80$ years. $^{7,8}$ In our patient population, only two patients (4.87\%) were under the age of 50 and $80.48 \%$ of the patients were between the ages of 60 and 80 . It is known that females are affected two or three times more frequently than males. ${ }^{9}$ One retrospective cohort study which included 304 patients reported that $75.3 \%$ of the patients were female. ${ }^{10}$ Higher female patient ratio with PMR changes between $55.26 \%$ and $69.64 \%$ was showed in a review, which was published in 2009.11 Likewise, significant female domination (78.08\%) was demonstrated in our study.

Hallmark symptoms of PMR include aching and prolonged morning stiffness in the shoulder girdle. Nearly all patients develop shoulder pain, while neck and pelvic girdle pain can also be present (approximately $70 \%$ and $50 \%$ of patients). ${ }^{12}$ Helliwell et al. ${ }^{10}$ reported that the most common symptom (45.7\%) was bilateral shoulder pain. Lee et al. ${ }^{13}$ reported that both shoulder and hip girdle pain were the most common symptoms (60.3\%) and shoulder girdle pain was seen in $25.7 \%$ of the patients. In our study population, the most common symptom was bilateral shoulder pain (59.09\%) followed by morning stiffness (48.48\%).

About $40 \%$ of PMR patients were reported to have systemic symptoms including low-grade fever, depression, fatigue, and weight loss. ${ }^{14}$ In our study, seven patients (17.7\%) developed fatigue and 16 patients (39.2\%) complained of severe myalgia.

Nearly half of the patients with PMR have distal musculoskeletal manifestations. In particular, one quarter of patients had arthritis, mainly of knees (40\%) and wrists (40\%). Metacarpophalangeal joints involvement was less common and could mimic rheumatoid arthritis. In a minority (about $12 \%)$ of patients, distal tenosynovitis and distal extremity swelling which is often referred to as RS3PE (remitting seronegative symmetrical synovitis with pitting edema) syndrome, was observed. Carpal tunnel syndrome in PMR has also been noted. ${ }^{15}$ Ceccato et al. ${ }^{16}$ showed that $39 \%$ of patients who had peripheral synovitis presented with pitting edema (5\%), carpal tunnel syndrome (5\%), and distal tenosynovitis (1.3\%). In our 41 patients with PMR, four patients (9.8\%) developed distal arthritis and 50\% of distal arthritis was knee arthritis. Carpal tunnel syndrome was not detected in these patients while monitoring for PMR. In this study, majority of the clinical features at presentation were similar to several previous reports from the literature although higher rates of morning stiffness and rare peripheral arthritis were observed in our patients.

Polymyalgia rheumatica is typically associated with giant cell arteritis (GCA). Population based studies have shown that $16-21 \%$ of patients with PMR have GCA, while PMR can also be present (40-60\%) in patients with GCA. ${ }^{12}$ In an epidemiological study from Korea, there was no GCA in patients with PMR. ${ }^{13}$ Similar to Korean patients, no GCA was detected in our study. This result may be associated with the ethnic differences.

Serious adverse events were reported due to the chronic use of low dose corticosteroids. In particular, increased osteoporotic fractures and cardiovascular disease draw attention. ${ }^{17}$ The use of bone protection when initiating steroids for PMR to prevent the complications of osteoporosis is recommended in the British Society for Rheumatology and British Health Professionals in Rheumatology guidelines for the management of PMR. ${ }^{18}$ Helliwell et al. ${ }^{10}$ reported that $4 \%$ of the patients in their study developed osteoporosis and $60.0 \%$ of the patients received prophylaxis for osteoporosis. In our study, 26 patients (63.41\%) received a prescription for osteoporosis (bisphosphonate and/or calcium + vitamin D). Nine patients $(21.95 \%)$ were using calcium + vitamin D supplements alone while 17 patients (41.5\%) were using bisphosphonate and calcium + vitamin D supplements together. Helliwell et al. ${ }^{10}$ reported that $18.4 \%$ of the patients complained of dyspeptic symptoms and $28 \%$ of the patients received prophylaxis for gastric symptoms. In our study, proton pump inhibitors or $\mathrm{H}_{2}$ antagonists were prescribed to $82.9 \%$ of the patients. 
Our approach to osteoporosis prophylaxis was similar to the literature, although gastric prophylaxis was more common in our patients. Recommendations for osteoporosis prophylaxis are mentioned frequently in the guidelines for PMR; however, no detailed information is available about gastric prophylaxis. Approaches to gastric prophylaxis may be different according to expert opinion, and patient population.

The standard treatment for PMR is lowdose glucocorticoids, which characteristically induce the rapid resolution of symptoms. ${ }^{19}$ The British Society for Rheumatology and British Health Professionals in Rheumatology guidelines suggested $15 \mathrm{mg} /$ day prednisolone for the first three weeks for the management of PMR. The suggested regimen is (i) daily prednisolone $12.5 \mathrm{mg}$ for the second three weeks, (ii) $10 \mathrm{mg}$ for 4- 6 weeks, and (iii) then reduction by $1 \mathrm{mg}$ every 4-8 weeks. ${ }^{18}$ However, initial prednisolone doses were reported differently in the literature as $21.5 \pm 8.3 \mathrm{mg} /$ day, $15 \pm 4 \mathrm{mg} /$ day, $15.8 \pm 8.4 \mathrm{mg} /$ day. ${ }^{10,13,17}$ The most common starting doses were $\geq 15 \mathrm{mg} /$ day in these studies. In our study, mean prednisolone dose was $17.4 \pm 4.2 \mathrm{mg} /$ day. The majority of the patients (56.1\%) received $20 \mathrm{mg} /$ day prednisolone.

Helliwell et al. ${ }^{10}$ reported that $72.7 \%$ of their patients had good response to corticosteroids and Lee et al. ${ }^{13}$ reported that approximately $40 \%$ of their patients had normal ESR in the first four weeks. Similarly, good response to the initial steroid was seen in $80.5 \%$ of patients in our study. It is known that PMR usually responds well to corticosteroids but not always. It seems that older patients may have better response to early treatment. Still, further studies are needed to determine the effect of age on the PMR treatment.

Disease-modifying antirheumatic drug therapy is recommended by British Society for Rheumatology and British Health Professionals in Rheumatology after two relapses. ${ }^{18}$ In a randomized double blind placebo controlled study, two groups were compared one of which received prednisolone and MTX $7.5 \mathrm{mg} /$ week, while the other was treated by prednisolone and placebo. At the end of the second year, no differences were detected between the MTX group and the placebo group concerning time to achieve remission, duration of remission, number of relapses, or cumulative prednisolone doses. ${ }^{20}$ Similarly, in two studies published in 2004 and 2007, no differences were found between the MTX group and placebo group cumulative prednisolone doses. ${ }^{21,22}$ In several clinics, DMARDs (azathioprine, leflunomid and hydroxychloroquine) have been used for separating patients from corticosteroids. ${ }^{13,23,24}$ Corticosteroid-related adverse events have occurred frequently, particularly in patients with relapsing disease. Consequently, new studies about the treatment of PMR with tocilizumab have drawn attention. ${ }^{25,26}$ Lee et al. ${ }^{13}$ reported that $30.8 \%$ of the patients used MTX and $61.5 \%$ of the patients used hydroxychloroquine. In our clinic, MTX is not used as a routine practice in patients with PMR. Two patients (4.87\%) received MTX, while the rest of the patients received prednisolone for the treatment of PMR. According to these results, our treatment approach seems more conservative and traditional.

Remission and relapse were evaluated in the patients. Seven patients (17.1\%) had remission and six patients (14.6\%) had relapse at least one time in our study. Lee et al. ${ }^{13}$ reported that $20.5 \%$ of their patients had remission and $46.1 \%$ of their patients had relapse. In another study from Korea, remission was reported for $15.7 \%$ and relapses were reported for $68.3 \%$ of the patients. ${ }^{27}$ Our relapse rate was lower than these reports; however, further studies with larger patient populations are needed to clarify the factors affecting relapse.

In conclusion, in our study, majority of the clinical features, initial steroid doses, and responses to corticosteroid therapy were similar to previous reports in the literature. Our patients with PMR were not associated with GCA. Good response to early steroid treatment was observed in older patients. Relapse rates were fairly low. Nevertheless, further studies are needed to evaluate the factors that affect response to treatment, remission, and relapse.

\section{Declaration of conflicting interests}

The authors declared no conflicts of interest with respect to the authorship and/or publication of this article. 


\section{Funding}

The authors received no financial support for the research and/or authorship of this article.

\section{REFERENCES}

1. Michet CJ, Matteson EL. Polymyalgia rheumatica. BMJ 2008;336:765-9.

2. Bruce W. Senile Rheumatic Gout. Br Med J 1888;2:811-3.

3. Bird HA, Esselinckx W, Dixon AS, Mowat AG, Wood $\mathrm{PH}$. An evaluation of criteria for polymyalgia rheumatica. Ann Rheum Dis 1979;38:434-9.

4. Chuang TY, Hunder GG, Ilstrup DM, Kurland LT. Polymyalgia rheumatica: a 10-year epidemiologic and clinical study. Ann Intern Med 1982;97:672-80.

5. Healey LA. Long-term follow-up of polymyalgia rheumatica: evidence for synovitis. Semin Arthritis Rheum 1984;13:322-8.

6. Dasgupta B, Cimmino MA, Kremers HM, Schmidt WA, Schirmer M, Salvarani C, et al. 2012 Provisional classification criteria for polymyalgia rheumatica: a European League Against Rheumatism/American College of Rheumatology collaborative initiative. Arthritis Rheum 2012;64:943-54.

7. Doran MF, Crowson CS, O'Fallon WM, Hunder GG, Gabriel SE. Trends in the incidence of polymyalgia rheumatica over a 30 year period in Olmsted County, Minnesota, USA. J Rheumatol 2002;29:1694-7.

8. Salvarani C, Cantini F, Boiardi L, Hunder GG. Polymyalgia rheumatica and giant-cell arteritis. N Engl J Med 2002;347:261-71.

9. Gonzalez-Gay MA, Vazquez-Rodriguez TR, LopezDiaz MJ, Miranda-Filloy JA, Gonzalez-Juanatey C, Martin J, et al. Epidemiology of giant cell arteritis and polymyalgia rheumatica. Arthritis Rheum 2009;61:1454-61.

10. Helliwell T, Hider SL, Mallen CD. Polymyalgia rheumatica: diagnosis, prescribing, and monitoring in general practice. Br J Gen Pract 2013;63:361-6.

11. Hernández-Rodríguez J, Cid MC, López-Soto A, Espigol-Frigolé G, Bosch X. Treatment of polymyalgia rheumatica: a systematic review. Arch Intern Med 2009;169:1839-50.

12. Salvarani C, Cantini F, Hunder GG. Polymyalgia rheumatica and giant-cell arteritis. Lancet 2008;372:234-45.

13. Lee JH, Choi ST, Kim JS, Yoon BY, Kwok SK, Kim $\mathrm{HS}$, et al. Clinical characteristics and prognostic factors for relapse in patients with polymyalgia rheumatica (PMR). Rheumatol Int 2013;33:1475-80.

14. Pipitone N, Salvarani C. Update on polymyalgia rheumatica. Eur J Intern Med 2013;24:583-9.

15. Salvarani C, Cantini F, Macchioni P, Olivieri I, Niccoli L, Padula A, et al. Distal musculoskeletal manifestations in polymyalgia rheumatica: a prospective followup study. Arthritis Rheum 1998;41:1221-6.

16. Ceccato F, Roverano SG, Papasidero S, Barrionuevo A, Rillo OL, Paira SO. Peripheral musculoskeletal manifestations in polymyalgia rheumatica. J Clin Rheumatol 2006;12:167-71.

17. Mazzantini M, Torre C, Miccoli M, Baggiani A, Talarico R, Bombardieri S, et al. Adverse events during longterm low-dose glucocorticoid treatment of polymyalgia rheumatica: a retrospective study. $\mathrm{J}$ Rheumatol 2012;39:552-7.

18. Dasgupta B, Borg FA, Hassan N, Barraclough K, Bourke B, Fulcher J, et al. BSR and BHPR guidelines for the management of polymyalgia rheumatica. Rheumatology (Oxford) 2010;49:186-90.

19. Kermani TA, Warrington KJ. Polymyalgia rheumatica. Lancet 2013;381:63-72.

20. van der Veen MJ, Dinant HJ, van Booma-Frankfort C, van Albada-Kuipers GA, Bijlsma JW. Can methotrexate be used as a steroid sparing agent in the treatment of polymyalgia rheumatica and giant cell arteritis? Ann Rheum Dis 1996;55:218-23.

21. Caporali R, Cimmino MA, Ferraccioli G, Gerli R, Klersy $\mathrm{C}$, Salvarani $\mathrm{C}$, et al. Prednisone plus methotrexate for polymyalgia rheumatica: a randomized, doubleblind, placebo-controlled trial. Ann Intern Med 2004;141:493-500.

22. Salvarani C, Macchioni P, Manzini C, Paolazzi G, Trotta A, Manganelli $\mathrm{P}$, et al. Infliximab plus prednisone or placebo plus prednisone for the initial treatment of polymyalgia rheumatica: a randomized trial. Ann Intern Med 2007;146:631-9.

23. De Silva M, Hazleman BL. Azathioprine in giant cell arteritis/polymyalgia rheumatica: a double-blind study. Ann Rheum Dis 1986;45:136-8.

24. Diamantopoulos AP, Hetland H, Myklebust G. Leflunomide as a corticosteroid-sparing agent in giant cell arteritis and polymyalgia rheumatica: a case series. Biomed Res Int 2013;2013:120638.

25. Al Rashidi A, Hegazi MO, Mohammad SA, Varghese A. Effective control of polymyalgia rheumatica with tocilizumab. J Clin Rheumatol 2013;19:400-1.

26. Macchioni P, Boiardi L, Catanoso M, Pulsatelli L, Pipitone N, Meliconi R, et al. Tocilizumab for polymyalgia rheumatica: report of two cases and review of the literature. Semin Arthritis Rheum 2013;43:113-8.

27. Kim HA, Lee J, Ha YJ, Kim SH, Lee CH, Choi HJ, et al. Induction of remission is difficult due to frequent relapse during tapering steroids in Korean patients with polymyalgia rheumatica. J Korean Med Sci 2012;27:22-6. 